\title{
MISCONCEPTIONS ABOUT EMOTIONAL INTELLIGENCE: DEPLOYING EMOTIONAL INTELLIGENCE IN ONE'S LIFE DIMENSIONS
}

\author{
ANOBÉ BADENHORST \\ anobe@swartberg.co.za \\ DAWIE SMITH \\ dsmith@uj.ac.za \\ Department of Human Resource Management \\ University of Johannesburg
}

\begin{abstract}
Emotional intelligence (EI) has become a buzz-word over the past ten years, yet misconceptions with regard to the concept abound. This leads to confusion among the general public, the scientific community, as well as to unfounded claims being made as to what the development of EI can accomplish in a person's life. In this article the aim is to clarify the concept EI by making a sharper demarcation between the Emotional Life Dimension and the other life dimensions. Based on this clarification, the conceptualisation of EI in the literature is reviewed in more depth.
\end{abstract}

Key words:

Emotional Intelligence, conceptual misconceptions

\begin{abstract}
Emotional intelligence has become a buzz-word and part of informed people's vocabulary over the past ten years. Large corporates as well as individuals are spending millions on training and workshops to improve emotional intelligence. A recent internet search done with emotional intelligence as a keyword yielded 9900000 results. Yet there is still confusion about the concept emotional intelligence (EI). Is EI in essence "to manage ourselves and our relationships with others so that we truly live our intentions", as stated by Lynn (2005, p. v.)? Does EI refer to "the array of personal-management and social skills that allows one to succeed in the workplace and in life in general" (Sterrett, 2000, p. 2)? Is "emotional aptitude (is) a meta-ability, determining how well we can use whatever other skills we have, including raw intellect" (Goleman, 1996, p. 36)? Or is EI more simply "involved in the capacity to perceive emotions, assimilate emotion-related feelings, understand the information of those emotions, and manage them" (Mayer, Salovey \& Caruso, 1999, p.1)? This apparent diversity in the conceptualization of EI leads to confusion with regard to the territory of EI, as well as to EI practitioners making claims that cannot be substantiated by addressing EI alone.
\end{abstract}

\section{Multiple theories with regard to the concept EI}

In the EI field numerous theories, models or views of EI exist. Theories of EI, upon which definitions of EI are based, are often classified into two basic types: those proposing a narrow definition of EI as an ability, based on the definition of Mayer et al. (1999), and those utilising a broader definition of EI, of which Goleman's approach is the most well-known (Zeidner, Matthews, Roberts, \& MacCann, 2003). These two approaches are also called "academic" versus "popular" (Emotional Intelligence View 360, 2004), or "ability" versus "mixed-model" (Mayer et al., 1999).

In their article "Emotional Intelligence: Issues and Common Misunderstandings", Emmerling and Goleman (2003, p. 9) point out that, while some might argue that the goal of research should be to identify and define a singular theoretical framework to be labelled as the "correct" version of EI, another approach would be to acknowledge that having multiple theories can often serve to elucidate additional aspects of complex psychological constructs. While this, on the surface, sounds like a fair argument, the problem is that many EI theorists make unfounded claims with regard to the scope of EI. This will be explained further on.
Caruso (2004, p. 2) comes up with an equally valid statement when he comments on Emmerling and Goleman's article. He writes:

If we, as researchers or practitioners, don't have a common language we cannot hope to effectively communicate with each other. We also risk alienating our clients as they struggle to understand what it is we have been selling them.

The lack of a common language is evident from the widely divergent definitions of EI quoted above. Caruso argues that, although writing for the general public is different to writing for the scientific community, the integrity of basic concepts, such as EI, should remain intact. The broadening of the concept EI has not been to the advantage of the EI field. One has to agree with Caruso's statement $(2004$, p. 4$)$ that there have been too many wild claims made in a frenzy to stake out territory during the gold rush of emotional intelligence.

\section{Criticism against the concept EI}

A review of literature reveals that the broadening of the definition of EI is one of the main criticisms levelled against efforts to define the concept (Daus \& Ashkanasy, 2003; Mayer et al., 1999). This broadening of the definition might be a result of the lack of a single, accepted definition of the concept, or in Caruso's terms, the lack of a common language. The lack of consensus on a single definition may also be connected to the other major criticisms of the concept, namely:

- EI overlaps with aspects of established personality theories and traits, especially the five factor theory. Daus and Ashkanasy (2003) note that the broad definitions of Goleman (1996) and Bar-On (1997) "do not appear to markedly differ from traditional personality models or competency models", and that "the Emotional Competence Inventory of Boyatzis, Goleman and Rhee (2000) tends to show quite substantial overlap with the Big Five (see for example, Davies, Stankov, \& Roberts, 1998; Dadwa \& Hart, 2000)". Davis (2004, p. 10) also states that some of the competencies identified by Goleman may not really be abilities at all (and thus would not technically qualify as a kind of intelligence), but may reflect personality traits instead.

- Measures of the construct are weak or problematic. The biggest problem in this regard, according to Davis (2004), is that self-report measures, the easiest ways to measure emotional quotient (EQ), are also the weakest ways to do it. Measurements of EI tend to be associated with the major EI models, and 
this has "allowed us to confuse EI models or theories with a specific measurement approach" (Caruso, 2004, p. 3).

- The degree to which EI is malleable, in contrast to the relative fixity of IQ, is contested by critics. Closely related to this is the view that EI is potentiality, and as such cannot be improved, although this potential can be developed or left undeveloped, as well as the issue of whether EI can be easily learned. Hein (2001, p.4) differentiates between emotional intelligence (EI), a person's innate potential, and EQ, "a relative measure of a person's healthy or unhealthy development of their innate EI".

- Claims made about the importance of EI cannot be substantiated. A lot of the debate revolves around the statement Goleman made that EQ can be more important to success at work than IQ (Goleman, 1996). This issue has been addressed and clarified by Emmerling and Goleman (2003). However, some claims are being made by EQ specialists about changes being affected to a person's life by developing one's EI that can clearly not be substantiated. Dann (2002, p. 31) for instance claims that "developing your EQ will help you if you are concerned with: ....your life-work balance because it must become more equitable and you need to renegotiate how your time is spent". Vermeulen states on her web site (www.theeqsite.co.za), that EQ is important "because it sets the stage for our ability to succeed at life", and that "If you're currently battling with any of the following then EQ is for you: Are you unhealthy, unfit?...Does your life lack purpose? Is it meaningless to you?" Unsubstantiated statements such as these could give rise to expectations that cannot be met through developing emotional competencies in isolation from the other life dimensions, as will be explained further on.

Unless greater clarity with regard to the concept is attained, the concept might be broadened to such an extent that the significance of EI, and its contribution to a greater understanding of the effective functioning of man, is lost.

\section{THE RESEARCH PROBLEM}

\section{The knowledge gap}

Despite the huge amount of literature available on EI, there still appears to be a knowledge gap:

- There is no single, universally accepted definition of EI.

It is evident that the EI field lacks a single, universally accepted definition of the concept emotional intelligence. This has been acknowledged by the major authorities on EI, such as Emmerling and Goleman (2003), and Caruso (2004). This leads to confusion among the audience (the general public as well as the scientific community), as well as to unfounded claims being made as to what the development of EI can accomplish in a person's life.

- There sometimes appears to be inconsistency when applying the stated definition of EI in developing EI.

In some instances there is also a considerable gap between the stated definition of EI, and the application of that definition when developing EI. Le Roux and De Klerk (2003), for instance, start off with a fairly narrow definition of EI, but broaden the concept when developing EI to include aspects such as values and self-acceptance.

- EI is not clearly demarcated.

In the introduction to their book, titled: "What is an emotion: Classic Readings in Philosophical Psychology", Calhoun and Solomon (1984, p. 6) state that, in approaching emotion theory, one of the most basic problems has to do with distinguishing between emotions and other mental phenomena. The problem of clarity of the concept EI can be addressed by demarcating the concept EI more clearly from one's other life dimensions. Because EI is not clearly demarcated from the other life dimensions, EI practitioners sometimes attribute improvement in functioning or well- being to the development of EI, while it should in fact be attributed to the development of other life dimensions, e.g. the Spiritual Dimension.

- There appears to be no documented holistic, integrated framework of how EI fits into the total person that can be applied when developing EI.

Authors such as Le Roux and De Klerk (2003), Vermeulen (1999), Dann (2002) and Goleman (1996) rightly include nonemotional aspects of the person, e.g. spirituality, morality, physical state and social relationships when developing EI. They do not, however, provide any conceptual framework of how these aspects link to EI, or of how EI fits into the functioning of the total person. Such a framework is provided by Smith, but has not been formally noted in academic literature.

\section{The objective of the research}

The primary objective of this article is to clarify the concept EI by putting EI in perspective with regard to the total person. To accomplish this objective, this article aims to:

- Position EI in the context of the eight life dimensions by making a sharper demarcation between the various life dimensions. Special emphasis will be placed on the spiritual life dimension, since many EI specialists unknowingly confuse EI with spirituality. Vermeulen (1999, p.9), for instance, states: "What's relevant is that the spiritual is the only source capable of generating power but it's managed by our emotional lives. ... We know too our emotions manage this force because when we feel good we're energetic." The irony, however, is that this should be the other way around. We feel good emotionally when we experience spiritual harmony, and for that matter, physical harmony.

- Illuminate the relationship between the Emotional Dimension and the other life dimensions

- Illustrate the misconception and confusion about the definition and scope of the concept EI in current literature

- Propose that the definition of Mayer, Caruso and Salovey (1999) be accepted as the definition of EI

- Introduce the concept of emotional leadership

- Propose that a holistic model of leadership development be applied when developing emotional leadership.

\section{Potential contributions of this study}

The potential contributions of this study are

- increased clarification of the concept EI by demarcating EI more clearly from the other life dimensions;

- identification of some of the misconceptions about EI, especially with regard to unfounded claims made by EI practitioners;

- to provide some insight into the links between EI and the other internal life dimensions; and

- documentation of Smith's framework as a foundation for the development of EI.

\section{METHODOLOGY}

The research approach followed in this study was non-empirical. Research methods used were a literature study and conceptual analysis. A literature study was undertaken to provide an overview of the definitions and scope of EI as applied in relevant literature. To this extent, current publications such as text books, theses, dissertations, and scientific journals, as well as those from the popular press and information available on the internet have been explored. Smith's PIPL perspective on EI forms an essential part of this study and his written works, workbooks for various workshops, as well as verbal communication were studied. Conceptual analysis means to explore the meaning of a specific construct or concept and can be defined as the analysis of the meaning of words or concepts through clarification and elaboration of the different dimensions of meaning (Mouton, 2004, p. 175). The meaning of the concept emotional intelligence was explored. 


\section{THE PERSONAL, INTERPERSONAL AND PROFESSIONAL LEADERSHIP (PIPL) PERSPECTIVE}

Prof D.P.J. Smith developed Personal, Interpersonal and Professional Leadership (PIPL), a relatively new multidisciplinary paradigm, currently being taught at the University of Johannesburg. Smith (2007a, p. 2) applies a systems theory approach towards a comprehensive, holistic view of man. According to Smith (2007a, p. 2), PIPL takes the integrated total well-being of a person as its focus. PIPL is based on anthropological premises, and grounded in existential reality and phenomenology. It therefore investigates and attempts to solve various phenomena that are characteristic of contemporary man and society, i.e. modern man's problems of existence (Du Toit, 2004). The scope of the article precludes an in-depth discussion of the presuppositions of PIPL. Of importance for this article, however, is the distinction made by Smith between intelligence and leadership.

The American Heritage Dictionary (Second Edition, 1982) defines intelligence as the capacity to acquire and apply knowledge. A person is born with numerous intellectual capacities and has the responsibility to optimally develop his abilities and skills in these capacities. Smith defines intelligence as an innate ability, potential or capacity. The optimal development of abilities and skills and the utilization of those abilities and skills in living an effective, successful and happy life is called personal leadership (Smith, 2007a, p. 8). Leadership requires commitment, willingness to grow, constructive use of abilities, responsibility, adding knowledge and a positive attitude. For instance, a person is born with a specific mental or cognitive intelligence, potential or capacity. The development and practical application of this intelligence is called mental leadership.

\section{Smith's Life Dimensions Model}

As stated above, this article aims to position EI in the context of the eight life dimensions by making a sharper demarcation between the various life dimensions. Smith (2007a, p. 3) distinguishes between four internal and four external life dimensions. The internal life dimensions are the spiritual, the physical, the mental and the emotional life dimensions. The external life dimensions are the social, one's career, one's financial dimension and the ecological life dimension. A model of the life dimensions is shown in Figure 1.

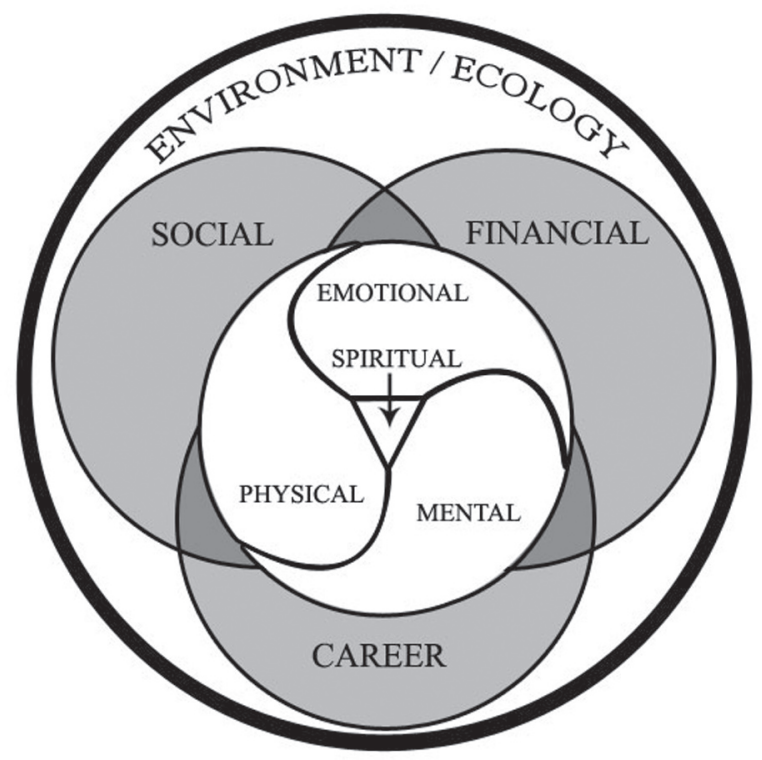

Figure 1: Smith's PIPL Life Dimensions Model
The dimensions of life and wellness define one's uniqueness, and help us understand who we are. The spiritual dimension is at the centre of a person's life. One's locus of control and the quality of one's life depend on the ability to balance one's internal life dimensions with the external. Although these eight dimensions can be distinguished from one another, they do not function in isolation, but are in constant systemic interaction with each other.

The focus of this article is the emotional dimension, one of the internal life dimensions. As the distinction between the internal and external life dimensions is fairly evident, the external life dimensions will not be discussed. The emotional dimension will be discussed first, whereafter the spiritual, physical, and mental dimensions will each be considered separately. The relationship between the emotional dimension and the other internal life dimensions will be investigated.

\section{The emotional dimension}

This dimension refers to emotions and feelings. The focus of this article on emotional intelligence requires a closer look at the concept emotion. The word emotion appeared in the English language in approximately 1660, and was borrowed from the Middle French émotion, derived from Old French emouvior, meaning to agitate, to stir up. It can be traced to the Latin word movre, to move out: ex-, out + movre, to move (Klein, 1966; American Heritage Dictionary, 1982; Barnhart, 1988). A review of dictionaries reveals that the current meaning of the word emotion includes: 1) an affective state of consciousness that involves feelings or sensibilities, as distinguished from cognitive and volitional states of consciousness (Simon \& Schuster, 2000; Webster's New World Dictionary of American English); 2) strong feeling, excitement, a state of agitation or disturbance (Oxford English Dictionary, 1961; Simon \& Schuster, 2000; Webster's New World Dictionary of American English); and 3) a complex and usually strong subjective response; any specific feeling, such as joy, sorrow, hate and love (Simon \& Schuster, 2000; American Heritage Dictionary, 1982; Webster's New World Dictionary of American English). The scientific investigation of emotions by a number of disciplines, including philosophy, theology, psychology, psychiatry, and the neurosciences, contributed to the formation of an array of divergent views of the concept emotion.

An excellent classification of the theories on emotion was made by Calhoun and Solomon (1984). Working from a philosophical perspective, they postulate that the modern debate about what an emotion is continues between the Jamesian theory on the one hand and the Aristotelian view on the other.

William James, an American philosopher and psychologist, originally trained in medicine, proposed a definition of emotion in an article published in 1885 . He defined emotion as the perception of physiological disturbances caused by an awareness of events and objects in the environment (Calhoun \& Solomon, 1984, p. 125). An object or event, for instance a snake, is perceived. In preparation for flight, the muscles involuntarily contract and respiration increases (physiological disturbances). The emotion (fear) is the perception of these physiological disturbances.

At the other end of the spectrum lies the theory of Aristotle, developed almost two-and-a-half thousand years ago. Aristotle saw beliefs, bodily motions and physiological changes as inseparable elements of emotions. He avoids a sharp distinction between mind and body, between the cognitive and physical elements of emotions. Calhoun and Solomon state that the Aristotelian view "...involves a concept of emotion as a more or less intelligent way of conceiving of a certain situation, dominated by a desire (for example, in anger, the desire for revenge)" (Calhoun \& Solomon, 1984, p. 3). 
Recent research in neurobiology and other neurosciences has contributed greatly towards our understanding of emotions. The neurologist Antonio Damasio (2004) bases his theory of emotion on this research. Damasio differentiates emotions from feelings, although he still sees the process of affect as a unified and apparently singular process $(2004$, p. 27). He offers what he calls a "working hypothesis of emotion-proper in the form of a definition", namely (Damasio, 2004, p. 53):

1. An emotion-proper... is a complex collection of chemical and neural responses forming a distinctive pattern.

2. The responses are produced in the normal brain when it detects an emotionally competent stimulus (an ECS), the object or event whose presence, actual or in mental recall, triggers the emotion. The responses are automatic.

3. The brain is prepared by evolution to respond to certain ECSs with specific repertoires of action. However, the list of ECSs is not confined to those prescribed by evolution. It includes many others learned in a lifetime of experience.

4. The immediate result of these responses is a temporary change in the state of the body proper, and in the state of the brain structures that map the body and support thinking.

5. The ultimate result of the responses, directly or indirectly, is the placement of the organism in circumstances conducive to survival and well-being.".

Damasio further postulates that feelings follow emotions, and defines a feeling as "the perception of a certain state of the body along with the perception of a certain mode of thinking and of thoughts with certain themes" (Damasio, 2004, p. 86). Bearing in mind that the emotional dimension encompasses both emotions and feelings as defined by Damasio, this dimension can be seen as complex collections of chemical and neural responses, trigged by emotionally competent stimuli, of which the immediate results are temporary changes in the state of the body and in the state of the brain structures, plus the perception of such bodily states along with the perception of modes of thinking and thoughts with certain themes. The raison d'etre of emotions and feelings is the placement of the organism in circumstances conducive to survival and well-being.

Smith (2005a) sees the emotional dimension as the expression of the integrated functioning of a multi-dimensional being. He describes emotions as expressions of one's:

- inner harmony or disharmony (spiritual dimension);

- meaningful or meaningless life (spiritual dimension);

- good or ill health ([hysical dimension);

- positive or negative thoughts (mental dimension) and

- fulfilling or unfulfilling relationships (social dimension).

Emotion is in most cases a feeling state of the inferred cognition (automatic or learned cognition) of a stimulus or event. It can be described in simple terms as how the person experiences a situation.

\section{The Spiritual Dimension}

One of the presuppositions upon which PIPL is based is that humans are spiritual beings (Smith, 2007a, p. 48). Zohar and Marshall (2001, p. 4) postulate: "We are driven, indeed we are defined, by a specifically human longing to find meaning and value in what we do and experience." The concept spirituality is difficult to define. In a recent article Smith and Louw (2007) states that there appears to be no universal definition of spirituality, and that the degree to which one can define the spiritual dimension from an intellectual perspective is limited. A very extensive and representative literature study of the conceptualisation of the spiritual dimension was done by Smith and Louw (2007). It was concluded by Louw that Smith's conceptualisation of the spiritual dimension makes an extremely valuable contribution because, among other reasons, it is comprehensive, descriptive and functional. Smith's conceptualisation of spirituality, as documented by Louw, is therefore accepted as the working definition of the spiritual dimension for this article. He sees the essence of spirit as beingness, i.e. where being finds expression (Smith \& Louw, 2007), and describes the spiritual self as "that vital part of us that transcends our temporary existence" (Smith \& Katz, 2006, p. 27). Smith developed PIPL as a functional science, with the broad objective of guiding a person toward an awareness and understanding of the essence of his own life and toward living a fulfilled life (Smith \& Louw, 2007). He therefore functionalises the concept spirituality, and translates it into concepts accessible to the ordinary person. Of particular importance for this article are the primary manifestations of spirituality identified by Smith (Smith \& Louw, 2007), i.e.: love, living in the present, simplicity, authenticity, gratitude, and stillness. Secondary manifestations, which can be seen as outcomes of living the primary manifestations of spirit, include connectedness, centeredness, harmony, peace, a sense of meaning, a sense of purpose, a sense of integration and wholeness, living what matters most (values), transcendence, positive expectations, an experience of profound beauty, wisdom, and intuition. Smith and Louw (2007) present a discussion of the primary and secondary manifestations of spirituality.

\section{The interaction between the emotional dimension and} the spiritual dimension

The connection between the emotional dimension and the spiritual dimension is not as well-researched as the connection between emotions, and, for instance, the physical dimension. A few studies on the effect of religiosity on emotional intelligence have been undertaken recently, for instance by Paek (2004). Smith (Smith \& Louw, 2007) has identified a religious orientation as one of the manifestations of spiritual leadership, but the spiritual dimension clearly encompasses much more than religiosity. In their article, entitled "Linking emotional intelligence, spirituality and workplace performance: Definitions, models and ideas for research", Tischler, Biberman and McKeage (2002) reviewed literature on both EI and spirituality. They concluded that EI and spirituality appear to lead to similar attitudes, behaviours and skills, and that many articles about spirituality tend to focus on or include emotional components, so that there often seems to be confusion, or at least intersection and linking, between the two constructs. These authors do not specify the definition of emotional intelligence on which they based their research, but quote Goleman's definition of EI, as well as an even broader definition postulated by Martinez. They propose several possible models of the linkage between EI and spirituality. The current article proposes that literature with regard to emotional intelligence often includes or focuses on components of the spiritual dimension.

As defined earlier, a feeling includes an awareness of a certain mode of thinking and of thoughts with certain themes. But where do these thoughts come from? The emotionally competent stimulus or activating event is perceived, interpreted (mental dimension) and evaluated. This evaluation is based on assumptions, attitudes, and beliefs. Our beliefs are based on our values, one of the secondary manifestations of spirituality. Our governing values and beliefs partly direct our behaviour and emotional response to events.

Smith views the spiritual dimension as the core of the individual - deficiencies in this dimension will lead to problems in the other life dimensions (Smith \& Louw, 2007). It is self-evident that living the primary manifestations of spirituality, as described by Smith (in Smith \& Louw, 2007), will have a profound effect on one's emotional dimension. Smith (in Smith \& Louw, 2007) describes spiritual love as characterised by its unconditional nature: it is non-judgmental, uncritical and accepting. This he translates in practical terms into unconditional acceptance, looking for the best in each person and in oneself, and treating others with respect. Smith identifies authenticity as another of the primary manifestations of spirituality. Several EI practitioners (Goleman, 1996; Dann, 2002; Cooper \& Sawaf, 2000) regard authenticity as an outcome of EI. Secondary manifestations, such as a deep 
centeredness, a sense of inner calm, harmony, peace, and inner control enable us to be emotionally stable - not becoming emotionally upset so easily. Connectedness to others enables us to express feelings such as caring, compassion and friendship, while connectedness to oneself leads to a positive self-image and selfacceptance. Having a sense of clear, direction-giving values helps us to understand our own emotions more easily, while an attitude of gratitude goes a long way in combating negative emotions.

Smith (2005a) illustrates the relationship between the emotional dimension and the other life dimensions by means of the metaphor of a motor car. The emotions represent the heat indicator on the dashboard, while the engine represents the body (physical dimension) and the spirit (spiritual dimension). The driver represents the mind (mental dimension). The faster the car is driven and the heavier the load, the higher the pressure on the engine. The heat indicators on the dashboard (emotions) will rise according to the heat and the speed. In order to control or lower the speedometer and the heat indicator, the driver needs to lower the speed or the pressure on the engine.

\section{The physical dimension}

This dimension encompasses the optimal wellness and health of all the parts and systems of the body, as well as the manner in which they function as a whole.

A person's state of health is often seen as the result of inherited genes. During the twentieth century scientists were devoted to linking specific genes to specific diseases (genetic determinism). However, as Capra (2003) illustrates in his chapter, entitled: "Biotechnology at a turning point", the concept of genetic determinism has been proven to be too simplistic. Holford (1998, p. 12) points out that a person's genetic make-up seems to be the result of highly complex interactions between the codes of numerous genes and the person's internal chemical environment. Furthermore, gene expression must be activated. Genes are turned on and off in response to specific signals. Our health is the result of the interaction between our genes and our environment or circumstances. The environment includes our internal chemical environment as well as our external environment. Our bodies try to function optimally and adapt to the stresses of life. Each person is born with a different genetic resilience or adaptive capacity. If a person's total environmental load exceeds his/her genetic capacity to adapt, disease may develop. This implies that every person is in charge of his own health. Although genes are inherited, the environment can determine how those genes are expressed. Holford (2004) describes the environment of your life as the sum total of everything you eat, drink, breathe, think and exercise.

Smith developed PIPL as a functional discipline based on the existential problems of modern man. He therefore focuses on those aspects of the physical dimension that have the biggest impact on quality of life, namely:

- cardiovascular health (According to Statistics South Africa (2006) 64092 people died in South Africa in 2004 of cerebrovascular diseases, other forms of heart disease or ischaemic heart diseases);

- physical strength; and

- flexibility (Smith, 2007b).

In the light of the high prevalence of obesity, hypokinetic diseases and unbalanced lifestyles, Smith emphasises the importance of nutrition and exercise for optimal physical health. Results of recent studies by the South African Medical Research Council indicate that nearly 50 percent of South Africans are overweight or obese, while 22 percent of children in the age group 1 to 9 years are overweight or obese (Van Heerden, 2006). As every person has to deal with aging, the biomarkers of aging are also addressed by Smith in his PPL workshops (Smith, 2007c), viz. muscle-to-fat ratio, strength, basal metabolic rate, aerobic capacity, blood sugar tolerance, cholesterol, blood pressure, bone density, and body temperature.
The interaction between the emotional dimension and the physical dimension

The scientific investigation of the link between emotions and physical health has sparked a lot of interest in recent years. The link between emotions and health is well-documented (see Karren, Hafen, Smith \& Frandsen, 2006). As we defined an emotion as a collection of chemical and neural responses, triggered by an emotionally competent stimulus, of which the immediate result is a temporary change in the state of the body and in the state of the brain structures, it is self-evident that the state of the body prior to experiencing the emotion would have an effect on the emotion. Likewise, the release of chemicals such as glucocorticoids into the bodily systems is known to have a huge effect on physical health (Karren et al., 2006, p. 45).

The state of the body prior to perceiving an emotionally competent stimulus plays a role in experiencing an emotion. To illustrate this role, the importance of the level of neurotransmitters such as serotonin in the brain can be considered. Neurotransmitters like serotonin, dopamine, noradrenaline and oxytocin activate certain circuits in the brain, producing a happy state (Illman \& Carter, 2004, p. 44). According to Ratey (2001), very high or very low levels of serotonin can contribute to aggression and anger - aggression has therefore been treated successfully with selective serotonin reuptake inhibitors (SSRIs) such as Prozac. A person with an abnormal level of serotonin may thus respond more severely to an emotionally competent stimulus, becoming much angrier than he would have, had his serotonin levels been normal. Low levels of serotonin are also associated with depression. Pert $(1999$, p. 267) states that the classical understanding of depression is that there is a shortage of the neurochemical serotonin secreted by the brain cells. It must be stressed that the link between neurochemicals and emotions is not a unilateral one. By definition emotions are chemical and neural responses resulting in changes in the body and brain structures. Thus, feeling happy, in turn, stimulates the production of "happy" neurotransmitters.

One of the most universal emotional responses of modern man is stress. Karren et al. (2006, pp. 45-47) describe twelve phases of the typical stress response - preparing the body for "fight or flight". While these processes are useful and may even be essential for coping with a stress-provoking situation, it is clear that continual stress is detrimental to physical health. These authors $(2006$, p. 59) state that some of the most common signs and symptoms of stress include headaches, backache, insomnia, tightness in the neck and shoulders, indigestion, loss of appetite or excessive eating, and a pounding heartbeat. They provide an overview of research on the effect of stress on various bodily systems, namely on the brain, the endocrine system, the gastrointestinal system, and the cardiovascular system. Holford and Cass (2001, pp. 10-18) provide a brief overview with regard to the interaction between neurochemicals and emotions. Excellent references for more detailed information are Pert (1999), LeDoux (1999), Ratey (2001), and Hammond (2005).

One aspect of the physical life dimension that we are able to control under normal circumstances is nutrition. Nutritionists are finding more and more evidence that what we eat and drink, or do not eat and drink, influences our emotions. Holford and Cass (2001, p. 106) quote research done at King's College Hospital, London, where it was found that 33 percent of patients with psychiatric disorders, including depression, were deficient in the B-vitamin foliate. They came to the conclusion that if we are poorly nourished, we are actually less able to cope with life's challenges. Nutrients (e.g. amino acids) are the building blocks of neurotransmitters. A lack of the amino acid tryptophan may, for instance, lead to a low serotonin level, and thus to feeling depressed (Holford \& Cass, 2001). 
The physical dimension encompasses certain aspects of the emotional dimension, but not all of it, while the emotional dimension encompasses certain aspects of the physical dimension, but also not all of it. However, it is clear that the two dimensions are intricately linked.

\section{The mental dimension}

According to Reber and Reber (2001) there has been so much bitter dispute as to the very nature of the human mind that it has never been entirely clear what this pertains to. They conclude that the term mental process is used to refer to a cognitive process. These authors state that cognition has traditionally been used to refer to activities such as thinking, conceiving and reasoning, while most psychologists use cognition to refer to any class of mental behaviours with underlying characteristics of an abstract nature, involving symbolizing, insight, expectancy, complex rule use, imagery, belief, intentionality, problem-solving and so forth. Mental intelligence is often seen as synonymous to Intelligence quotient (IQ), as measured by instruments such as the Wechsler Adult Intelligence Scale (WAIS) and the Stanford-Binet Scale. IQ tests measure abilities such as reasoning, imagination, insight, judgement, adaptability, abstraction, learning and dealing with novelty (Reber \& Reber, 2001). These aspects of the human mind can be referred to as intellect.

However, the mind encompasses much more than just intellect. De Beauport (2002) regards the abilities measured by traditional IQ tests as rational intelligence, and expands the concept mental intelligence to also include associative intelligence, spatial intelligence and intuitive intelligence. Smith's PIPL-perspective on the Mental Dimension is far more inclusive, addressing aspects such as the conscious mind as well as the subconscious mind, the power of thought, conditioned mindset, belief windows, attitude, and temperament (Smith, 2007c).

An important aspect of the mental dimension's bearing on the emotions is the temperament of the person. Smith (2007d) has done substantial research in this regard, upon which his PIPLTemperament Typology is based. He describes temperament as the psychological outcome of one's DNA composition, the chemical composition of one's blood, hormones that enhance or inhibit certain physical and psychological function, the nature of one's central nervous system and brain dominance (Smith, 2007d, p. 3). The manner in which temperament is expressed, depends to a large extent on the dominant mindset of the person. Mindset can be defined as a fixed mental attitude or disposition that predetermines a person's responses to and interpretations of situations (www.answers.com/topic/mindset). Smith (2007c, p. 3:1) describes mindsets as deep beliefs, attitudes, prejudices, views and norms that we hold about ourselves, people, our environment and the world we live in.

\section{The interaction between the emotional dimension and the mental dimension}

With regard to the emotional dimension, having mental abilities enables us to:

- sense, experience and interpret events;

- assess situations on the basis of our feelings;

- express our feelings; and

- manage our feelings, e.g. through rational choice (Smith, 2005a).

Damasio (2004, p. 86) defines a feeling as the perception of a certain state of the body, along with the perception of a certain mode of thinking and of thoughts with certain themes. Thoughts are clearly seated in the mental dimension, while the awareness of these thoughts, along with an awareness of the state of the body, creates a feeling (in the emotional dimension). The contents of the thoughts have a direct bearing on the feeling.

The cognitive-behavioural school of counselling, represented by theories such as Ellis's rational-emotive behaviour therapy (Ellis, 2004), and Beck's cognitive behaviour therapy (CBT)
(Illman \& Carter, 2004), is based on the premise that what we think influences the way we feel. These theories focus on thoughts, beliefs, assumptions and perceptions. They propose that the way we feel about an event (an emotionally competent stimulus, or, in Ellis's terms, an activating event) depends largely on what we think about the event. Ellis (2004) uses his ABC model to explain this phenomenon, where:

$\mathrm{A}=$ an Activating event: what the person perceives (or an emotionally competent stimulus);

$\mathrm{B}=$ Belief: what the person believes about what he perceives (including thoughts, modes of thinking, belief systems);

$\mathrm{C}=$ Consequence: his reaction, including his feelings. This is not a reaction to "A", but to "A" plus "B" (Ellis, 2004, p. 32)

These theories attempt to help the individual who is experiencing problems change the way he feels by changing his thoughts, beliefs or assumptions to more helpful ones.

The way we express our feelings is influenced by our temperament type. Smith (2007d) describes the difference in expression of feelings for each of his four temperament types. An L1 person, will, for instance tend to bottle up or repress feelings, while an R2 person tends to be very expressive. Different temperament types also react differently to stress.

Conversely, the way we feel also affects our way of thinking. Caruso and Salovey (2004, pp. 17-19) refer to research done on the interaction of mood and thinking. They point out that emotions, both positive and negative, influence our way of thinking. Positive emotions expand thinking, help generate new ideas, and encourage us to consider possibilities. Negative emotions narrow our field of attention and perception, leading to a clearer focus that allows details to be examined more efficiently, and motivates a more efficient search for errors. Damasio (2004, p. 85) confirms this, stating that sadness, for example, is accompanied by low rates of image production and hyperattentiveness to images, rather than by the rapid image change and short attention span that goes with happiness. An experiment conducted by Damasio and his colleagues found a marked deactivation in the prefrontal cortices while a person is experiencing sadness, and an increase in activity in this region of the brain when a person is experiencing happiness (Damasio, 2004, p. 101).

\section{MISCONCEPTIONS ABOUT EMOTIONAL INTELLIGENCE (EI)}

\section{Defining EI}

Mayer et al. (1999) define EI as the ability to a) perceive and identify emotions; b) use emotions to facilitate thought; c) understand emotions; and d) manage emotions. Goleman (1996, p. 34) defines EI as: "abilities such as being able to motivate oneself and persist in the face of frustrations; to control impulses and delay gratification; to regulate one's moods and keep distress from swamping the ability to think; to empathize and to hope." He suggests 20 independent and important EI competencies clustered in four categories: Self-Awareness; Self-Management; Social Awareness; and Relationship management. Some EQ specialists broaden the concept even further, as illustrated by the above-mentioned definition proposed by Lynn (2005).

Some of the definitions of EI can be challenged, because they do not clearly demarcate EI from the other life dimensions, such as the spiritual, mental and social dimensions. A summary of some of the definitions of EI that are available in literature, followed by an indication of the life dimensions actually involved, is presented in Table 1.

It is clear that most of these definitions, with the exception of the definition of Mayer et al. (1999), include aspects of life dimensions other than the emotional life dimension. They therefore do not clearly distinguish between the emotional and other life dimensions. 
TABLE 1

\section{Definitions of EI}

\begin{tabular}{|c|c|c|}
\hline 1) & $\begin{array}{l}\text { BAR-ON (1988) Traits } \\
\text { theory: }\end{array}$ & Life Dimension \\
\hline & $\begin{array}{l}\text { To be aware of, to understand } \\
\text { and to express oneself } \\
\text { To be aware of, to understand } \\
\text { and to relate to others } \\
\text { Ability to deal with strong } \\
\text { emotions } \\
\text { To adapt to change } \\
\text { To solve problems of } \\
\text { a personal nature } \\
\text { a social nature }\end{array}$ & $\begin{array}{l}\text { - Includes aspects of the physical } \\
\text { and mental dimensions } \\
\text { - Includes aspects of the social and } \\
\text { spiritual dimensions } \\
\text { Relies strongly on the spiritual } \\
\text { dimension } \\
\text { - Relies strongly on the mental } \\
\text { and spiritual dimensions. } \\
\text { Could also involve the physical } \\
\text { dimension. } \\
\text { Includes aspects of the mental, } \\
\text { and spiritual Dimensions. } \\
\text { solving problems of a social } \\
\text { nature involves the social } \\
\text { dimension. }\end{array}$ \\
\hline
\end{tabular}

\section{2) Mayer, Salovey and Caruso Life Dimension} (1999)

- Become aware of one's own feelings (ability to perceive one's emotions)

- Emotional dimension

- Emotional dimension

- Emotional dimension

Ability to use these emotions/

the right mood to assist

thought (what and how one thinks)

- To understand the underlying causes of one's emotions and to build one's emotional knowledge base

- To reflectively regulate/manage one's emotions and thereby promote emotional decision making and actions

3) Goleman, 1999, p. 318) Life Dimension

- Self-awareness: Knowing what we are feeling

- Self-regulation: Handling our emotions

- Motivation: Using our deepest preferences to move and guide us toward our goals

- Empathy: Sensing what people are feeling

- Social skills: Handling emotions in relationships

\begin{tabular}{ll}
\hline 4) Cooper \& Sawaf, (2000) & Life dimension \\
\hline - Emotional Literacy: being & - Spiritual dimension \\
real and true to yourself, & - Spiritual dimension and social \\
inner guidance, Connection, & dimension \\
Intuition, honesty & - Spiritual dimension \\
- Emotional Fitness: Authentic & - Spiritual dimension \\
Presence, resilience, trust & \\
- Emotional Depth: Integrity, & \\
Commitment, Purpose & \\
Emotional Alchemy: Intuitive \\
flow, reflection, situational \\
transformation
\end{tabular}

Some EI specialists define EI in a narrow sense, but broaden the concept when applying it in developing EI. Le Roux and De Klerk (2003, p. 10), for instance, define EI in terms of abilities:

Emotional intelligence is a type of personal and social intelligence, which includes the following:

- the ability to perceive, recognise, understand and react to the feelings of yourself and those of others (emotional awareness);

- the ability to distinguish between various feelings and to name them (emotional literacy);

- the ability to express and control your feelings appropriately (emotional control);

(Then they start broadening their definition)

- the ability to listen to others, to have empathy with them, and to communicate effectively in terms of emotions and thoughts, and
- to use the information in directing your thoughts and actions so that you live effectively, are motivated, and have a goal in mind (relation between thoughts, feelings and behaviour).

When applying the concept they include aspects such as values and assumptions, self-knowledge, self-image, self-acceptance, and self-assertiveness, without providing a conceptual framework of how these aspects are linked to EI

\section{Unfounded claims}

EI practitioners, in their endeavour to stake out territory, make claims with regard to EI that are mostly unaccounted for. Some of the traits and competencies that EI specialists claim to develop as a result of "emotional" intelligence intervention are listed in Table 2 below. A number was used to refer to each source. The index to the sources occurs at the bottom of the table.

Goleman's full list of corporate emotional competencies, as presented in his 1998 book, reads as follows: emotional awareness, accurate self-assessment, self-confidence, trustworthiness, conscientiousness, adaptability, innovation, achievement drive, commitment, initiative, optimism, understanding others, developing others, service orientation, leveraging diversity, political awareness, influence, communication, conflict management, leadership, change catalyst, building bonds, collaboration and cooperation, and team capabilities. In looking at this list it is also fairly easy to see that it includes nearly everything that is not IQ (see http://www.emotionaliq. org). (In fairness, this list has now been adapted, albeit only slightly).

TABLE 2

COMPETENCIES ASCRIBED TO THE DEVELOPMENT OF EI

\begin{tabular}{ll}
\hline Trait/competency & Ascribed to EI by \\
\hline authenticity & $1 ; 2 ; 4$ \\
transparency & 4 \\
Intuition & $1 ; 4 ; 6$ \\
value centered living & $2 ; 4 ; 6$ \\
Integrity & $1 ; 3 ; 6$ \\
self-management, self control & $2 ; 3 ; 7$ \\
self-awareness & $1 ; 2 ; 4 ; 5 ; 6$ \\
better thought process, problem solving & $1 ; 2 ; 3$ \\
sense of presence, personal influence & $1 ; 4 ; 5 ; 6$ \\
adaptability & $2 ; 3 ; 4$ \\
self-knowledge, self-image, self-acceptance, & $2 ; 6$ \\
assertiveness, choices & \\
Balance & $2 ; 3$ \\
communication & $3 ; 6$ \\
coping with stress & $2 ; 4$ \\
goal-setting & $4 ; 6$ \\
purpose, vision & $1 ; 4 ; 5$ \\
self-motivation & $2 ; 6$ \\
trust, trustworthiness & $1 ; 2 ; 4$
\end{tabular}

Index of sources:

(1) Cooper \& Sawaf, 2000; (2) Dann, 2002; (3) Emotional Intelligence 360 View, 2004; (4) Goleman, 1996; (5) Lynn, 2005; (6) Sterrett, 2000; (7) Vermeulen, 1999.

A number of quotes will indicate typical unfounded claims of EI practitioners:

- "Emotions can serve as our inner moral and ethical compass" (Dann, 2002, p. 27).

- Competency for self-control: Authenticity. To have this competency you would:

- build trust through your reliability and congruent behaviour;

- act ethically;

- stand up for your values (Dann, 2002, p. 143). 
- Some of Cooper \& Sawaf's (2000, p. xxxii) statements about what EI can do for you:

- executive EQ begins with intuition, responsibility, and connection. Builds personal power - including awareness, inner awareness, inner guidance, respect;

- emotional fitness strengthens your authenticity, believability, and resilience;

- evidence indicates that a person's fundamental values and character in life stem above all, not from IQ, but from underlying emotional capacities.

- Lynn $(2005$, p. vi) says about the power of EI: "In essence EI is about managing ourselves and our relationships with others so that we truly live our intentions. EQ is the distinguishing factor between finding and living our life's passions or just putting in time".

- And last, but not least, Vermeulen's (1999, p. 9) statement that our emotions manage the spiritual (quoted at the beginning of this article).

It is clear that failing to acknowledge the role of the spiritual dimension in the development of emotional leadership leads to most of these misconceptions about EI.

\section{CLARIFYING THE CONCEPT EI: EI VERSUS EMOTIONAL LEADERSHIP}

The lack of a single universally accepted definition of EI clearly leads to a broadening of the concept, which in turn gives rise to confusion of the audience and unfounded claims being made by EI practitioners. This issue needs to be addressed urgently.

Caruso (2004, p. 3), in his argument for a common language, proposes a dictionary of EI terms as a starting point. He suggests defining the following three entries as the starting point, summarizing their explanations in Table 3.

TABLE 3

Approaches to Defining EI

\begin{tabular}{lll}
\hline Term & Current Approach & Related to \\
\hline Trait approach & $\begin{array}{l}\text { Traits related to adaptation } \\
\text { and coping (e.g. } \\
\text { assertiveness) }\end{array}$ & $\begin{array}{l}\text { Models of personality } \\
\text { and dispositional traits }\end{array}$ \\
$\begin{array}{l}\text { Competency } \\
\text { Approach }\end{array}$ & $\begin{array}{l}\text { Acquired skills and } \\
\text { competencies underlying } \\
\text { effective leadership (e.g. } \\
\text { influence) }\end{array}$ & $\begin{array}{l}\text { Leadership competency } \\
\text { models. }\end{array}$ \\
Emotional & $\begin{array}{l}\text { Intellectual abilities using } \\
\text { emotional information (e.g. } \\
\text { Intelligence }\end{array}$ & $\begin{array}{l}\text { Models of general, or } \\
\text { standard, intelligence. }\end{array}$ \\
\hline
\end{tabular}

Caruso (2004, p. 3) further states:

To be less subtle, what I am proposing is that for a model to be considered and called emotional intelligence it must combine emotion with intelligence. Calling traits such as assertiveness or influence emotional intelligence just does not seem to be helpful.

This statement is strongly endorsed. As illustrated above, all the other definitions of EI include aspects of life dimensions other than the emotional dimension. It is therefore advocated that the definition of Mayer et al., (1999) as adhered to by Davis (2004) and Salovey and Caruso (2004), should be the accepted definition of EI. Emotional skills and competencies that underlie effective leadership, as referred to above by Caruso, should rather be termed emotional leadership.

Goleman (2004) proposes that: "emotional intelligence and EI competence are intimately related, but not of the same order. Rather, one emerges from the other". According to him,
EI competences are based on EI, but require cultivation over years throughout a person's life, or intentionally cultivating EI competences with a proper model of learning. Goleman (2004) further states that: "EI mingles neocortical and subcortical skills, combining affective and cognitive abilities". This article proposes that emotional leadership not only combines affective abilities (emotional dimension) and cognitive abilities (mental dimension) but also abilities from all the other life dimensions, drawing heavily on the spiritual dimension in particular.

\section{DISCUSSION}

\section{Interpretation}

It was initially stated that the main objective of this article was to clarify the concept EI by putting EI in perspective with regard to the total person. This was done by utilising Smith's Life Dimensions Model. Demarcating the four internal life dimensions, namely the spiritual, physical, mental and emotional dimensions, clarifies what the emotional dimension is, and, more importantly for this article, what it is not.

When studying relevant literature with a clearer concept of EI in mind, the following become apparent:

- Misconceptions about the nature and scope of EI abound. These misconceptions often lead to claims made by EI practitioners about what the development of EI can accomplish in a person's life, which cannot be substantiated by developing EI alone. A review of claims made by EI practitioners indicated that many of the traits and competencies attributed to the development of EI should, in fact, rather be attributed to the development of spiritual leadership, as these traits involve the spiritual dimension and not the emotional dimension.

- These misconceptions can partly be ascribed to the lack of a single, universally accepted definition of EI. A review of a number of definitions presented in the literature showed that life dimensions other than the emotional dimension are often included in the broader definitions of EI. Based on the demarcation of the life dimensions, the conclusion was drawn that only the "narrow" definitions of EI, such as the definition proposed by Mayer et al. (1999), are valid definitions of EI. Emotional skills and competencies underlying effective leadership should rather be termed emotional leadership.

- In addition to having no clear concept of the nature and scope of EI, most EI practitioners also lack a conceptual framework of how EI fits into the total person, or fail to explicitly state their framework. Smith's Life Dimensions Model provides such a framework, and the connection between the emotional dimension and each of the other internal life dimensions was illustrated. This is of particular importance, as most of the EI practitioners are involved in the development of EI.

Recommendations for developing emotional leadership: the need for a conceptual framework of the emotional dimension in perspective with regard to the total person Although many EI specialists draw on the spiritual dimension when developing emotional competencies, most do not acknowledge the fact that the spiritual dimension is involved in developing emotional leadership. Those specialists who do, e.g. Vermeulen (1999), do not have a clear model of the link between the two. The spiritual dimension is the core of a person, and spiritual leadership has a profound effect on emotional leadership, i.e. the optimal development of emotional intelligence.

This article proposes that all the life dimensions need to be taken into account when developing emotional leadership competences within a holistic model of how EI fits into one's life dimensions. Smith's Life Dimensions Model provides such 
a framework. In terms of this model, developing emotional leadership should involve not only the emotional dimension, but also include all the other life dimensions, as they each have a bearing on emotional leadership.

The spiritual dimension is of particular importance for the development of emotional leadership. This dimension forms the foundation for emotional leadership. Most EI practitioners agree that values and assumptions determine emotional needs (Le Roux \& De Klerk, 2003). These are manifestations of spirit. It is essential that this dimension be specifically addressed when developing emotional leadership. Developing the spiritual dimension along with the emotional dimension will also help to avoid what Hein (2003) calls "the dark side of EI": to use emotional intelligence to become hurtful, manipulative, greedy, controlling, and arrogant; or depressed and suicidal.

Although not discussed in this article, it should be noted that the external life dimensions, viz. the social, financial, career and ecological dimensions, are also important. For instance, the social dimension - a person's social support system, or lack of such a system, could have a meaningful impact on his ability to cope with his emotions. To get along adequately with others, we need more than emotional skills: the essence of good interpersonal relationships (social dimension) is determined primarily by what Smith $(2007 \mathrm{c})$ calls the three A's: the ability of authenticity (Cashman, 1998; McGraw, 2000), the ability of acceptance (Rogers, 1961; Ruiz, 1999; McGraw, 2001; Buscaglia, 1984), and the ability to add value to self and others (Cashman, 19981; Covey, 1999).

\section{CONCLUSION}

It is in the interest of the EI community to clarify the confusion surrounding the nature and scope of EI, otherwise the significance of EI might be diminished. A single, universally accepted definition of EI is needed. To evaluate the different definitions presented in the literature, it is necessary to distinguish clearly between emotions and other life dimensions. Smith's Life Dimensions Model provides a framework for demarcating the emotional dimension, and for explaining how the emotional dimension is linked to the other life dimensions. Based on this demarcation, it is clear that the only definition of EI that defines intelligence exclusively with regard to emotions is that of Mayer et al. (1999). All the other definitions include aspects of the other life dimensions, mostly of the spiritual dimension. The definition of Mayer et al. (1999) should therefore be accepted as the universal definition of EI. The other definitions that were reviewed, define emotional leadership, rather than EI.

Smith's Life Dimension Model provides an extremely valuable conceptual framework for the development of emotional leadership. This model not only demarcates the emotional life dimension from the other life dimensions, but also provides insight into the connections between the different life dimensions.

EI, or rather emotional leadership, is not the only factor determining the effectiveness, success or well-being of a person: it is not more or less important than leadership in any of the other life dimensions. This article strongly endorses Smith's view of man as a multi-dimensional being, while emotions are seen as the expression of the integrated functioning of this multi-dimensional being. Although emotions are very important, they are, in Smith's metaphor of the motor car, only the indicators of what is going on in the engine. If the engine overheats due to too much pressure, the situation cannot be rectified by replacing the heat indicator. It is therefore strongly advocated that emotional leadership be developed within a holistic framework, including all the other life dimensions, with particular emphasis on the spiritual dimension.

\section{REFERENCES}

The American Heritage Dictionary Second Edition. (1982). Boston: Houghton Mifflin Company.

Barnhart, R.K. (editor) 1988. The Barnhart Dictionary of Etymology. USA: The H.W. Wilson Company.

Bar-On, R. (1988). The development of an operational concept of psychological well-being. Unpublished doctoral dissertation. Pietermaritzburg, Rhodes University.

Buscaglia, L.F. (1984). Loving each other. New York: Fawcett Columbine.

Caruso, D.R. \& Salovey, P. (2004). The Emotionally Intelligent Manager. How to Develop and Use the Four Key Emotional Skills of Leadership. San Francisco: Jossey-Bass.

Caruso, D. (2004). Comment on R.J. Emmerling and D. Goleman; Emotional Intelligence: Issues and Common Misunderstandings: Defining the Inkblot Called Emotional Intelligence. http://www.eiconsortium.org.

Calhoun, C, \& Solomon, R.S. (eds). (1984) What is an emotion? Classic Readings in Philosophical Psychology. New York: Oxford University Press.

Capra, F. (2003). The hidden connection. London: Flamingo.

Cashman, K. (1998). Leadership from the inside out. USA: Executive Excellence Publishing.

Cooper, R.K. \& Sawaf, A. (2000). Executive EQ. Emotional Intelligence in Business. London: Texere.

Covey, S.R. (1999). The Seven Habits of Highly Effective People. London: Simon \& Schuster.

Damasio, A. (2004). Looking for Spinoza. Joy, sorrow and the feeling brain. London: Vintage.

Dann, J. (2002). Emotional Intelligence in a week. London: Hodder $\&$ Stoughton.

Daus, C.S. \& Ashkanasy, N.M. (2003). Will the Real Emotional Intelligence Please Stand Up? On Deconstructing the Emotional Intelligence "Debate", http://siop.org/tip/Oct03/16daus.htm.

Davis, M. (2004). Test your EQ: Find out how Emotionally Intelligent you really are. London: Piatkus.

De Beauport, E. (2002). The three faces of Mind. Think, feel, and act to your highest potential. Wheaton: Quest Books.

Du Toit, C.S.M. (2004). Individual facilitation: A personal and professional leadership perspective. Unpublished D-Phil Thesis. Johannesburg: Rand Afrikaans University.

Ellis, A. (2004). The Road to Tolerance: The Philosophy of Rational Emotive Behavior Therapy. New York: Prometheus Books.

Emmerling, R.J., \& Goleman, D. (2003) ). Emotional Intelligence: Issues and Common Misunderstandings. Consortium for Research on Emotional Intelligence in Organizations. http:// www.eiconsortium.org.

Emotional Intelligence View 360. (2004). Facilitator's Guide. Santa Monica: Organizational Performance Dimensions.

Goleman, D. (1996). Emotional Intelligence. Why it can matter more than IQ. London: Bloomsbury.

Goleman, D. (1999). Working with Emotional Intelligence. Great Britain: Bloomsbury.

Goleman, D. (2004). Comment on D. Caruso, Defining the Inkblot Called Emotional Intelligence: Apples and Applesauce .http://www.eiconsortium.org.

Hammond, C. (2005). Emotional rollercoaster. A journey through the science of feelings. London: Fourth Estate.

Hein, S. (2001). Understanding Emotional Intelligence. .http:// hr.com/hrcom/index.cfm/WeeklyMag/94A83EB2-59C311D5-9AC6009027EO248F.

Hein, S. (2003). The Dark Side of Emotional Intelligence. http:// eqi.org/dark1.htm

Holford, P. (1998). 100\% Health. London: Piatkus.

Holford, P. (2004). New Optimum Nutrition Bible. London: Piatkus. Holford, P. \& Cass, H. (2001). Natural Highs. London: Piatkus.

Illman, J. \& Carter, R. (2004). Use your brain to beat depression. The complete guide to understanding and tackling depressive illness. London: Cassell Illustrated.

Karren, K.J., Hafen, B.Q., Smith, N.L. \& Frandsen, K.J. (2006). Mind/Body Health. The Effects of Attitudes, Emotions, and Relationships. Boston: Allyn and Bacon. 
Klein, E. (1966) A Comprehensive Etymological Dictionary of the English Language. Volume 1. Amsterdam: Elsevier Publishing Company.

LeDoux, J. (1999). The Emotional Brain: The Mysterious Underpinnings of Emotional Life. London: Phoenix.

Le Roux, R. \& De Klerk, R. (2003). Emotional Intelligence Workbook: The all-in-one guide for optimal personal growth. Cape Town: Human \& Rousseau.

Lynn, A.B. (2005). The EQ Difference. A Powerful Plan for Putting Emotional Intelligence to Work. New York: AMACOM.

Mayer, J.D., Caruso, D.R., \& Salovey, P. (1999). Emotional Intelligence Meets Traditional Standards for an Intelligence. Ablex Publishing Corporation.

McGraw, P.C. (2000). Relationship Rescue. London, Vermilion.

McGraw, P.C. (2001). Self Matters. London: Simon \& Schuster.

Mouton, J. (2004). How to succeed in your Master's \& Doctoral Studies. A South African guide and resource book. Pretoria: Van Schaik Publishers.

The Oxford English Dictionary. (1961). London: Oxford University Press.

Paek, E.S.K. (2004). The role of religiosity in emotional intelligence: An empirical study of Christians. Unpublished doctoral dissertation. USA : New York University.

Pert, C.B. (1999). Molecules of Emotion: Why you feel the way you feel. London: Pocket Books.

Ratey, J. (2001). A user's guide to the brain. London: Abacus.

Reber, A.S. \& Reber, E.S. (2001) The Penguin Dictionary of Psychology (Third edition). London: Penguin Books.

Rogers, C.R. (1961). On becoming a person: A therapists view of psychotherapy. Boston: Houghton Mifflin.

Ruiz, D.M. (1999). The mastery of love. San Rafael: Amber-Allen Publishing.

Simon \& Schuster (2000). New millennium dictionary and thesaurus. Available on CD: Simon \& Schuster Interactive.

Smith, D.P.J. \& Louw, M. (2007). Conceptualisation of the spiritual life dimension: a Personal and Professional Leadership perspective. SA Journal of Human Resource Management, 5(1).
Smith, D.P.J. (2007a) The PiPL Perspective. Johannesburg: University of Johannesburg.

Smith, D.P.J. (2007b). Study Guide, Module 7: Personal Health and total well-being. Unpublished notes. Johannesburg: University of Johannesburg.

Smith, D.P.J. (2007c). Personal and Interpersonal Leadership Workbook. Johannesburg: Minuteman Press.

Smith, D.P.J. (2007d). The PiPL-Temperament Typology. . Johannesburg: University of Johannesburg

Smith, D.P.J. \& Katz, R. (2006). Spiritual leadership: Readings for $M B A$ elective. Stellenbosch: Business School, University of Stellenbosch.

Smith, D.P.J. (2005a). Misconceptions about EI: Deploying EI in one's life dimensions. Unpublished paper delivered to the NexusEQ Conference, June 2005, Amsterdam.

Statistics South Africa (2006). Mortality and causes of death in South Africa, 2003 and 2004. Findings from death notifications. Pretoria: Statistics South Africa. http://www.statssa.gov.za.

Sterrett, E.A. (2000 ). The Manager's Pocket Guide to Emotional Intelligence. Amherst: HRD Press.

Tischler, L., Biberman, J., \& McKeage, R. (2002). Linking emotional intelligence, spirituality and workplace performance: Definitions, models and ideas for research. Journal of Managerial Psychology, 17, (3): 203-218.

Van Heerden, I. (2006). Are South Africans gluttons? http://www. health24.com/dietnfood/

Weight Centre/15-51-2954-2960,36121.asp.

Vermeulen, S. (1999). EQ. Emotional intelligence for everyone.

Cape Town: Zebra Press.

Webster's New World Dictionary of American English, Third College Edition, Cleveland: Webster's New World.

Zeidner, M., Matthews, G., Roberts, R.D. \& MacCann, C. (2003). Development of Emotional Intelligence: Towards a MultiLevel Investment Model. Human Development, Mar-Jun; (46): 2-3; Academic Research Library p.69.

Zohar, D. \& Marshall, I. (2001). SQ: Spiritual Intelligence: the ultimate intelligence. London: Bloomsbury. 